\title{
Duplication of urethra
}

INSERM

\section{Source}

INSERM. (1999). Orphanet: an online rare disease and orphan drug data base. Duplication

of urethra. ORPHA:237

Duplication of the urethra is a rare congenital genitourinary anomaly, encompassing a wide spectrum of anatomic variants in which the urethra is partially or totally duplicated, which may be asymptomatic or cause symptoms such as incontinence, recurrent urinary infections and difficulty urinating. 